\title{
Genetic Diversity and Inbreeding in a Captive Population of the North Persian Leopard (Panthera pardus saxicolor L.)
}

\author{
Ana Marquiza M. Quilicot ${ }^{1}$ and Roswitha Baumung ${ }^{2}$
}

${ }^{1}$ College of Veterinary Medicine, Visayas State University, Baybay, Leyte, 6521-A Philippines, ${ }^{2}$ Division of Livestock Sciences, University of Natural Resources and Life Sciences, Gregor-Mendel Strasse 33, 1180 Wien, Austria

\begin{abstract}
Information on the degree of inbreeding is very important in the effective management of captive populations of animals in zoos. For the North Persian leopard (Panthera pardus saxicolor), in particular, no report on this aspect is available. This study evaluated the effect of inbreeding on fitness traits and the possible occurrence of purging in a captive population of the leopard based on pedigree records of the Australasian Regional Association of Zoological Parks and Aquaria covering the period 1955-2008. The significance of individual, sire or dam inbreeding on individual and litter fitness traits and litter size was analyzed using linear mixed models. Results showed that individual inbreeding significantly decreased survival at days 30 and 90 (weaning age) after birth, while litter inbreeding significantly decreased litter survival at days 7, 30 and 90. There was also a corresponding decrease in litter size when the dam was inbred. Purging of genetic load is possible with increased survival of the individual and litter when the dam was inbred. However, enhanced zoo management has to be considered with increased survival of individuals. Considering the unpredictable response of traits to inbreeding, designing breeding programs for captive populations should be geared toward maximizing genetic diversity and minimizing the rate of inbreeding.
\end{abstract}

Key Words: total inbreeding, fitness traits, purging in captive populations, North Persian leopards

Correspondence: R. Baumung. Address: Division of Livestock Sciences, Gregor-Mendel Strasse 33, 1180 Wien, Austria .E-mail:roswitha.baumung@boku.ac.at DOI: $10.32945 /$ atr3417.2012 


\section{INTRODUCTION}

Captive breeding of endangered or threatened animal populations is becoming more important as part of the measures to maintain genetic diversity and avoid inbreeding depression (Hedrick, 1994). Captive populations may also serve as a reservoir of genetic material that can be utilized for the re-establishment or reinforcement of wild populations and, thus, considered essential in the prevention of extinction of a species (Read and Harvey, 1986; Lacy, 1993). Animals in ex situ conservation are also expected to have an improved survival rate as genetic resource when they are reintroduced into the natural population (Ramirez etal., 2006).

Since population sizes in zoos are usually small, inbreeding is unavoidable, which leads to unfavorable consequences such as inbreeding depression. This major risk factor in captive populations of threatened species elevates the risk of extinction in inbred captive populations (Frankham et al., 2001). Loss of genetic diversity is another consequence, which is due to increase in homozygosity and founding event (founding effect) as subsequent generations emerge or when there is minimum exchange of animals between institutions (Richards, 2000). The response to inbreeding depression varies between traits wherein traits that involve fitness are the ones critically affected. Fitness traits include survival (number of young that survived); disease resistance; stress resistance and reproduction traits such as fertility, ejaculate volume, mating ability, female fecundity (number of eggs laid, embryogenesis) and litter size (Read and Harvey, 1986; Hedrick, 1994; Falconer and Mackay,1996; Lacy et al., 1996; Crnokrak and Roff, 1999; Amos and Balmford, 2001;Keller and Waller, 2002). Inbreeding depression is accounted in captive, laboratory and wild populations (Ralls et al., 1979; Crnokrak and Roff, 1999; Wright et al., 2008). It is also recognized as an important factor in determining the fitness of small populations (Kalinowski and Hedrick, 1999).

Inbreeding also increases the frequency of genotypes homozygous for deleterious alleles, resulting in selection against these alleles, thus purging the genetic load. Purging results in an increase of fitness of a population under random mating with a balance between mutation and selection (Hedrick, 1994). Purging has been studied in a number of species. Frankham et al. (2001) cited the works of Ballou (1997) which observed 
small effects of purging in captive mammals, and Visscher et al. in 2001, which revealed purging in a small feral population of Chilligham cattle in England.

To date, no published report is available on the genetic diversity and the occurrence of inbreeding depression and purging in a captive population of the North Persian leopard (Panthera pardus saxicolor Linnaeus). This species is commonly found in the wild range in the Middle East and is declared as endangered by the International Union for the Conservation of Nature (Khorrozygan, 2008). Information on genetic diversity and the occurrence of inbreeding depression and purging of genetic load in the population of interest is important in assessing vulnerability to extinction and the degree of genetic variation loss.

This paper presents the effect of inbreeding to fitness traits (survival at days 7, 30 and 90 - weaning age) and the possible occurrence of purging in North Persian leopards kept and documented in 170 zoos worldwide within the last 55 years.

\section{MATERIALS AND METHODS}

Data

The data used and analyzed in this study were obtained from the studbook records of the North Persian leopard in SPARKS (Single Population Analysis and Records Keeping System) format. The studbook is maintained by a studbook keeper of Association of Zoo and Aquaria (AZA) which coordinates with the World Association of Zoos and Aquariums (WAZA) and other AZA regional Studbook. Identity number of the individual, sire and dam; sex; birth date; death date or date indicating the last update of the individual in the studbook; parity number; location of birth (zoo) and litter size were the important information used during the analyses.

\section{Classical inbreeding coefficient}

The classical inbreeding coefficient (f) is the probability that the two alleles in homologous loci of an individual are identical by descent from a common ancestor of the parents. Therefore, $\mathrm{f}$ indicates the relationship 
between the parents of the individual. This coefficient is used to examine the general effect of inbreeding on the traits of interest. The individual's classical inbreeding coefficient was calculated using the GRain program in the PEDIG software package (Boichard, 2002).

\section{General linear mixed models}

A general linear mixed model was used to evaluate the effect of inbreeding on fitness traits (individual and litter survival, and litter size). Survival traits include neonatal survival up to 7 and 30 days of age, and survival to weaning age at 90 days. Survival up to 30 days is included in the analyses to have additional mortality records. Survival is computed based on the date of birth of the individual up to the death date.

Individuals were coded as either not surviving (0) or surviving (1) at an age of 7 or 30 days, or at the weaning age of 90 days. A litter was coded as surviving (1) if more than $50 \%$ of the individuals within it survived; otherwise, it was coded as not surviving (0). Individuals with missing death dates and no update information were excluded from the analyses.

Parity numbers beyond 10 were clustered to 10 . Birth type, which refers to the litter size, was coded as 3 when the litter size is more than 3 for the analyses of the individual/litter survival.

The survival traits were considered binary, while litter size was regarded as normally distributed. Data restrictions were made based on fitness trait analyzed and the number of observations per zoo-year combination. Zoo-years with only one observation were excluded from the analyses for all survival traits. A dam within zoo-year effect was considered a fixed effect for all the survival trait analyses, since the study is aiming not to compare the performance of zoos with regard to survival of the individuals. Fixed effects included in the analyses for the survival traits were sex, parity number and birth type (litter size). For the analysis of litter size, the dam was considered a random effect. Fixed effect of sex is excluded from the analyses of litter mortality, since no sex code for a litter is applicable. Fixed effect of birth type is excluded in the analyses for litter size.

Model 1 includes the individual, sire and dam classical inbreeding coefficients for the survival trait analysis of the North Persian leopards 
$u=u_{0}+\beta_{f} f+\beta_{f f} f_{s}+\beta_{f f} f_{d}+\beta_{\text {Sex }}$ Sex $+\beta_{\text {ParityP }}$ Parity\# $+\beta_{\text {BirthType }}$ BirthType

where $u, \quad$ logit transformation of a measure of fitness such as mortality;

$u_{0} \quad$ mean fitness of non-inbred animals;

$f \quad$ classical inbreeding coefficient of the individual/litter;

$f_{\mathrm{s}} \quad$ classical inbreeding coefficient of the sire;

$f_{\mathrm{d}} \quad$ classical inbreeding coefficient of the dam;

Sex sex of the individual;

Parity\# parity number (1-10);

BirthType litter size to which the individual belongs to (1-3)

$\beta_{f} \beta_{f s}, \beta_{f \mathrm{f}}, \beta_{\text {Sex }}, \beta_{\text {Parityt }}$ and $\beta_{\text {Birthype }}$ are the regression coefficients associated with $f, f_{\mathrm{s}}, f_{\mathrm{d}}$, Sex, Parity\# and BirthType

The effect of individual, sire and dam classical inbreeding coefficients to survival traits of captive North Persian leopards was analyzed with the SAS procedure GLIMMIX (v. 9.2 Statistical Analysis Systems Institute Inc., Cary, NC), while their influence on litter size was analyzed with the SAS procedure MIXED (v. 9.2 Statistical Analysis Systems Institute Inc.).

Mortality risk at 7 days, 30 and 90 (weaning age)

The mortality risk of an individual or litter at days 7, 30 and 90 at a certain level of inbreeding was calculated based on the formula below

$$
\hat{\pi}(x)=\frac{\exp (\text { intercept }+ \text { parameter estimate } x)}{1+\exp (\text { intercept }+ \text { parameter estimate } x)}
$$

Where $\hat{\boldsymbol{\pi}}(\boldsymbol{x})$ indicates the probability of mortality of an individual or litter, and $x$, the level of inbreeding. Probabilities of mortality with the categorical traits were based on the least square means obtained from the output of the SAS procedure GLIMMIX using option ilink.

Litter size

The degree of inbreeding effects on litter size was calculated based on the least square estimates from the output of the SAS procedure 
MIXED, with regression coefficients showing an increase or decrease in number of cubs per $10 \%$ increase in inbreeding. The following model was used: $y_{i j k}=\mu+\mathrm{pn}_{i}+b_{f} f_{1}+b_{f \mathrm{f}} f_{\mathrm{s}}+b_{f} f_{\mathrm{d}}+d_{k}+\varepsilon_{i j k}$

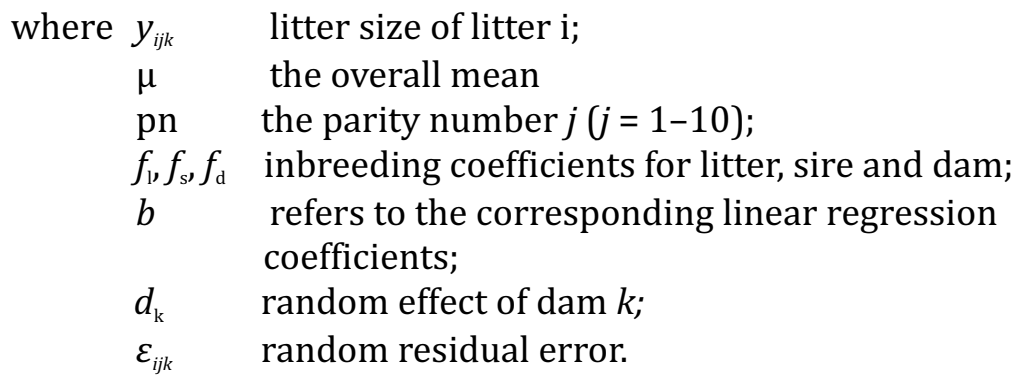

\section{RESULTS AND DISCUSSION}

The features of the North Persian leopard studbook record is shown in Table 1. Individual/litter, dam and sire inbreeding coefficients, sex, parity number and birth type where included in the general linear mixed model for the analysis of individual/litter mortality risk at days 7, 30 and 90 (weaning age). Litter, dam and sire inbreeding coefficients and parity number are included in the analysis of the relationship of inbreeding and litter size.

Table 1. Pedigree characteristics of the North Persian leopard (1955-2008)

\begin{tabular}{ll}
\hline No. of animals in the pedigree & 639 \\
No. of living animals & $144(22.54 \%)$ \\
No. of males & $272(42.47 \%)$ \\
No. of females & $275(43.04 \%)$ \\
No. of sires with offspring & $84(13.14 \%)$ \\
No. of dams with offspring & $89(13.92 \%)$ \\
No. of litters or parities & 339 \\
Litter size, mean & $1.81(1-5$, S.D. $=0.80)$ \\
Parity number, mean \& range & $3.20(1-11$, S.D. $=2.20)$ \\
Pedigree record period & $1955-2008(53$ years $)$ \\
No. of zoos* with the species & 170 \\
*Stillbirths included & \\
**Association of Zoo and Aquaria (AZA)-Accredited Zoos \\
Figures in parentheses is the percentage of animals in relation to the total \\
population of North Persian leopards registered in the studbook
\end{tabular}


Mortality riskat 7 days, 30 and 90 (weaning age)

To analyze the effect of inbreeding as well as purging in the captive population of North Persian leopards, classical inbreeding coefficients of individual/litter, sire and dam were included in the general linear mixed model analyses for the mortality risk at days 7, 30 and 90 (weaning age).

The mean, standard deviation and range of the individual/litter, sire and dam classical inbreeding coefficients of the North Persian leopard are presented in Table 2 . Approximately $70 \%$ of the individuals (448 out of 639 ) and litters (247 out of 353 ) were inbred. The lowest classical inbreeding coefficient of inbred individuals was almost 0.25 (0.2497).

Table 2. Classical inbreeding coefficients (f) of individual/litter, sire and dam.

\begin{tabular}{lcccc}
\hline & Mean & $\begin{array}{c}\text { Standard } \\
\text { deviation }\end{array}$ & Minimum & Maximum \\
\hline Individual & 0.1293 & 0.1143 & 0.0000 & 0.3975 \\
Litter & 0.1260 & 0.1136 & 0.0000 & 0.3975 \\
Sire & 0.0741 & 0.1063 & 0.0000 & 0.3690 \\
Dam & 0.0593 & 0.0971 & 0.0000 & 0.3012 \\
\hline
\end{tabular}

Figure 1 shows the relationship of classical inbreeding coefficients and mortality risk at days 7, 30 and 90 (weaning age). The dam classical inbreeding has a significant effect on mortality ( $\alpha$-level 0.10 ), while individual classical inbreeding was only significant in survival at days 30 and 90. The sire classical inbreeding coefficient is not significant in all survivability analyses. The classical inbreeding coefficients of the individual and dam have opposite effects on the survival of the individual.

In the litter survival analyses, results showed that only the dam classical inbreeding coefficient was significant in mortality at days 7 ( $p<$ $0.05), 30(\mathrm{p}<0.05)$ and $90(\mathrm{p}<0.10)$ (Figure 2), indicating that as the dam classical inbreeding coefficient increases, mortality risk of the litter decreases, which means that the chances of survival of the litter is higher when the dam is inbred. On the other hand, increase of litter classical inbreeding coefficient points into another direction. As litter classical inbreeding coefficient increases, mortality risk increases. However, the effect of litter classical inbreeding coefficient was not significant in any analyses. 


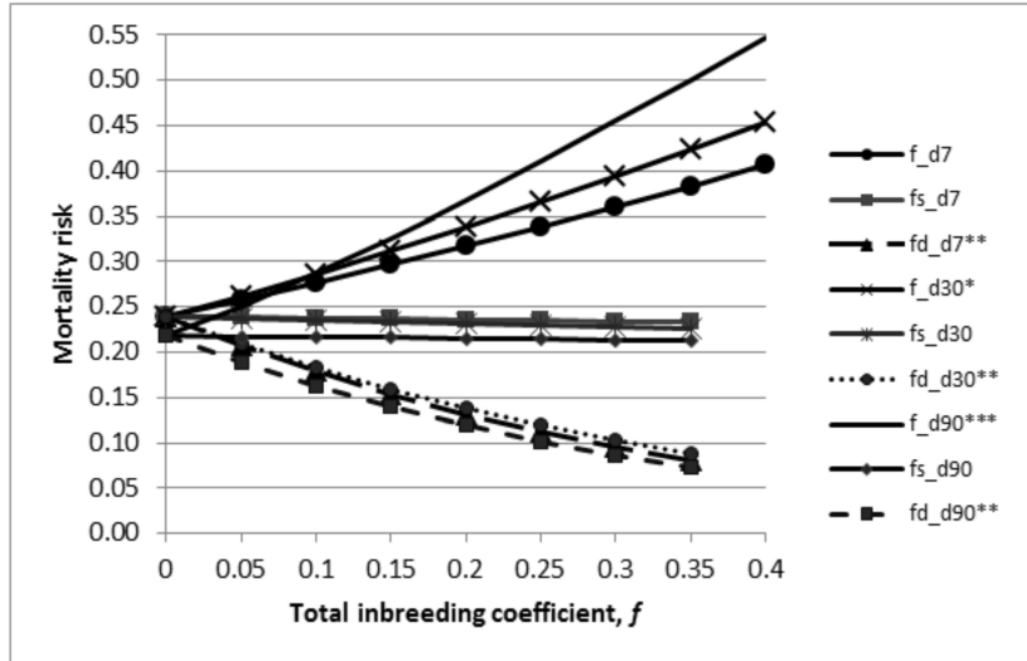

$p<0.10, " p<0.05, \cdots p<0.01, \cdots p<0.001$.

$f=$ Individual inbreeding coefficient; $f_{\mathrm{s}}=$ sire inbreeding coefficient; $f_{\mathrm{d}}=$ dam inbreeding coefficient; $\mathrm{d} 7$ $=$ day $7 ; \mathrm{d} 30=$ day 30 ; and $\mathrm{d} 90=$ day 90 .

Figure 1. Mortality risk of an individual at days 7, 30 and 90 (weaning age) with classical inbreeding coefficients $(f)$ of individual, sire and dam.

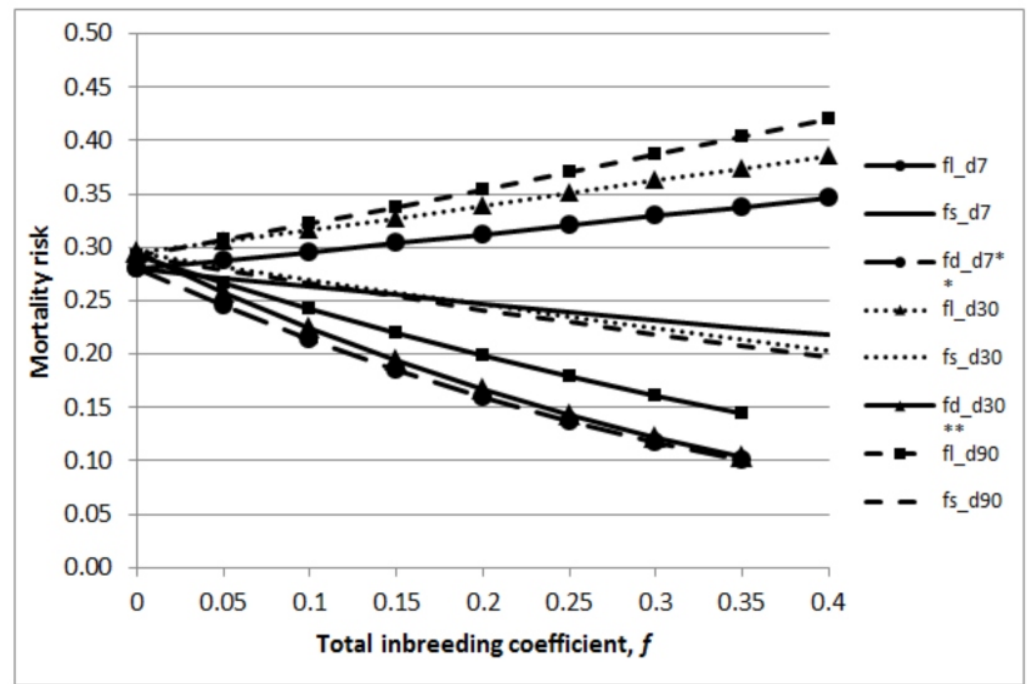

classical inbreeding coefficients $(f)$ of litter, sire and dam. " $p<0.10, " p<0.05,{ }^{\prime \prime} p<0.01, \cdots p<0.001$.

$f_{1}=$ inbreeding coefficient of the litter; $f_{\mathrm{s}}=$ inbreeding coefficient of the sire; $f_{\mathrm{d}}=$ inbreeding coefficient of the dam; $\mathrm{d} 7=$ day $7 ; \mathrm{d} 30=$ day $30 ;$ and $\mathrm{d} 90=$ day 90 .

Figure 2. Mortality risk of litter at days 7, 30 and 90 (weaning age) with classical inbreeding coefficients $(f)$ of litter, sire and dam. 
The results indicated that inbreeding due to individual/litter, sire or dam has different effects on the individual/litter survival. Individual inbreeding influences the survival at days 30 and 90 (weaning age). Cassell et al., (2003) mentioned reduced fitness such as survival results from increasing inbreeding coefficient. The decrease in survival in relation to inbreeding could be due to an increase in homozygosity of deleterious alleles, resulting in inbreeding depression (Crnokrak and Roff, 1999; Read and Harvey, 1986; and Wright et al., 2008). Inbreeding depression refers to the decrease in fitness such as survival of inbred individuals (Leberg and Firmin, 2008). Studies performed in the wild and in captivity showed that inbred offspring are less likely to survive than non-inbreeds (Bales et al., 2001; Brown and Brown, 1998; Packer and Pusey, 1993; Ralls et al., 1979).

Inbreeding of the dam has a significant effect on survival trait (survival at days 7, 30 and 90), which could be an indication of purging, in which, as dam inbreeding increases, the probability of individual and litter mortality also decreases. Ballou (1997) detected a positive effect of dam inbreeding in European bison (Bison bonasus), while Lacy et al. (1996) and Margulis (1998) observed a positive effect of dam inbreeding in the viability of oldfield mouse (Peromyscus polionotus). Margulis (1998) considered that inbred dams have improved maternal behaviour, which contributed to the increased survival of the litter, but reproductive success is reduced. Moreover, it was also found out that inbred females will more likely experience pseudopregnancy, which is due to extended luteal phase and increased progesterone levels (Margulis, 1998). The increase in progesterone levels enhances the manifestation of maternal behaviour, which favors survival of the offspring (Dwyer, 2008). Nevertheless, the result in this study is in contrast with the findings of Boakes et al. (2006) with the 119 zoo populations where maternal inbreeding has a negative effect on fitness.

\section{Liter size}

The relationship of litter, sire and dam inbreeding on litter size was evaluated with linear mixed model analyses. The following sections discuss the results of the analyses.

The effect of classical inbreeding of litter, sire and dam on litter size is illustrated in Figure 3. Increased inbreeding of litter and sire has a slight positive or no effect on the litter size. However, only the classical inbreeding of the dam has a significant negative effect on litter size. Maternal 
inbreeding had a negative effect on litter size $(\mathrm{p}<0.10)$. Studies of Lacy et al. (1996) on oldfield mice and Beresken et al. (1968) on pigs also showed inbreeding depression in the form of decreased litter size from inbred dams. The inbreeding depression in the litter size associated with dam inbreeding can be due to the effect of the dam inbreeding on embryo survival in early gestation (Cassell et al., 2003). McCarthy (1967) in his study with mice associated the decrease in litter size with a reduction in the number of eggs ovulated and increase in preimplantation mortality in inbred mothers. Rodrigañez et al. (1998) also mentioned that litter size is determined by the genotype of the dam and not the litter. Van Avendoketal. (1996) also revealed the presence of maternal genetic influence on piglet survival. Maternal effects on the litter could be considered environmental to the offspring but can have both genetic and environmental components. Furthermore, Periparto et al. (2002) in their study identified two quantitative trait loci that were affecting maternal performance such as nest building, pup grooming, lactation and aggression towards intruders which are essential for the survival of the offspring.

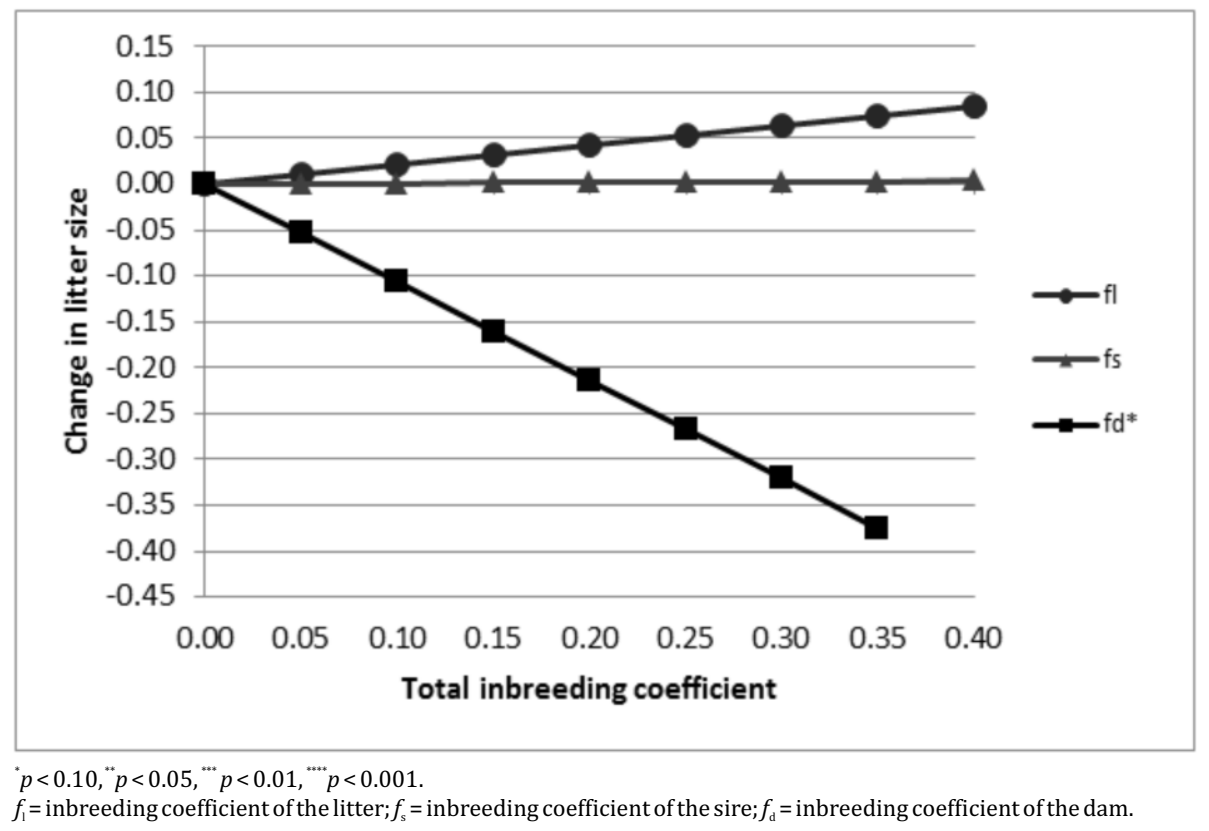

Figure 3. The effect of classical inbreeding of litter, sire and dam on litter size. 
Effects of sex, paritynumber and size

Effects of sex of the individual and parity number were found to be insignificant on the survival of individual or litter in contrast to birth type $(\mathrm{p}<0.10)$. Birth type in this study is defined as the size of the litter to which the individual belongs to. The average litter size in North Persian leopards is 2.40 (S.D. $=0.71$ ). Figure 4 shows the distribution of birth types and the type of rearing provided. Singles have higher a probability (0.51-0.55) of mortality compared to twins and triplets, with probabilities ranging from 0.22 to 0.32 and from 0.25 to 0.27 , respectively. However, it was not evaluated if the difference between birth types is significant, since it is beyond the scope of the study. Approximately, $43.85 \%$ of the population was born with a twin, $33.75 \%$ as triplets or more and $22.40 \%$ as singles.

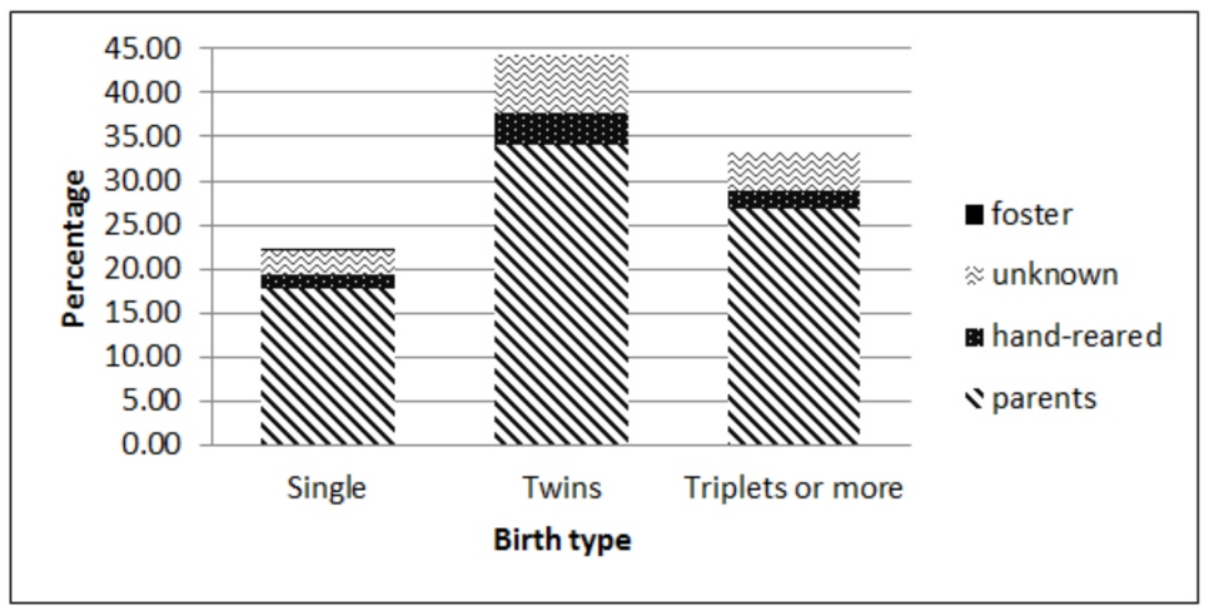

\section{CONCLUSIONS}

Inbreeding depression is apparent with an increased mortality risk up to days 7, 30 and 90 (weaning age) after birth as the individual/litter classical inbreeding coefficient increases. Furthermore, the decrease in litter size is significantly associated with increasing litter and dam inbreeding. Purging could be presumed present when the increasing dam classical inbreeding coefficient is significantly associated with the increase in the chances of individual/litter survival. Conversely, this increase in survival could also be associated with improved zoo management.

This study shows that fitness traits will have different responses to 
various inbreeding levels, considering that they are influenced by many alleles. The use of molecular methods is suggested to validate the genetic diversity and inbreeding level of the target population.

Furthermore, the unpredictable response of traits to inbreeding should be considered in designing breeding programs for captive populations in order to maximize genetic diversity and minimize the rate of inbreeding, thus, prevent the extinction of this species.

\section{ACKNOWLEDGMENT}

The author thanks Dr. Elizabeth Boakes of the NERC Centre for Population Biology, Imperial College, Berkshire, UK, and Ros Wilkins, North Persian Leopard Species Management Officer of the Association of Zoos and Aquaria for the data used in this study.

\section{REFERENCES}

AMOS, W., and A. BALMFORD. 2001. When does conservation genetics matter? Heredity 87: 257-265.

BALES, K., M. HERRON, A.J. BAKER, and J.M. DIETZ, 2011. Sources of variability in numbers of live births in wild golden lion tamarins (Leontopithecus rosalia). American Journal of Primatology 54:211-221.

BALOU, J.D. 1997. Ancestral inbreeding minimally affects inbreeding depression in mammalian populations. Heredity 88: 169-178.

BERESKEN, B., C.E. SHELBY, K.E. ROWE, W.E.URBAN, C.T. BLUNN, A.B. CHAPMAN, V.A. GARWOOD, L.N. HAZEL, J.F. LASLEY, W.T. MAGEE, J.W. MCCARTY, and J.A. WHATLEY, 1968. Inbreeding and swine productivity traits. Journal of Animal Science 27: 339-350.

BOAKES, E.H., WANG, J. and W. AMOS. 2006. An investigation of inbreeding depression and purging in captive pedigreed populations. Heredity 1-11.

BOICHARD, D. 2002. Pedig: A fortran package for pedigree analysis suited to large populations. $7^{\text {th }}$ World congress on Genetics Applied to Livestock Production, Montpellier, 19-23 août 2002, pp. 28-13. 
BROWN, J.L., and E.R. BROWN. 1998. Are inbred ofsrping less fit? Survival in a natural population of Mexican jays. Behavioral Ecology 9(1): 60-65.

CASSELL, B.G., V. ADAMEC, and R.E. PEARSON, 2003. Maternal and fetal inbreeding depression for 70-day nonreturn and calving rate in Hosteins and Jerseys. Journal of Dairy Science 86: 2977-2983.

CRNOKRAK, P., and D.A. ROFF. 1999. Inbreeding depression in the wild. Heredity 83: 260-270.

DWYER, C.M. 2008. Genetic and physiological determinants of maternal behaviour and lamb survival: inputs for low-input sheep management. Journal of Animal Science, 86: 246-258.

FALCONER, D.S., and T.F.C. MACKAY, T. F. C. 1996. Introduction to quantitative genetics. $4^{\text {th }}$ Edition. Longman Group Ltd., England.

FRANKHAM, R., D.M. GILLIGAN, D. MORRIS, and D.A. BRISCOE. 2001. Inbreeding and extinction: Effects of purging. Conservation Genetics 2: 279-285.

HEDRICK, P.W. 1994. Purging inbreeding depression and the probability of extinction: full-sib mating. Heredity 73: 363-372.

KALINOWSKI, S.T., and P.W. Hedrick. 1999. Detecting inbreeding depression is difficult in captive endangered species. Animal Conservation 2: 131-136.

KELLER, L.F. and D.M. WALLER. 2002. Inbreeidng effects in wild populations. Trends in Ecology and Evolution 17(5): 230-241.

KHORROZYGAN, I. 2008. Panthera pardus ssp. saxicolor. In: IUCN 2008. 2008 I UCN Red List of Threatened Species. $<$ http://www.iucnredlist.org>. Downloaded on 26 April 2009.

LACY, R.C. 1993. Impacts of inbreeding in natural and captive populations of invertebrates: implications for conservation. Perspectives in Biology and Medicine 36: 480-496. 
LACY, R.C., G. ALAKS, and A. WALSH. 1996. Hierarchical analysis of inbreeding depression in Peromyscus polionotus. Evolution 50(6): 2187-2200.

LEBERG, PL. and B.D. FIRMIN. 2008. Role of inbreeding depression and purging in captive breeding and restoration programmes. Molecular Biology 17: 334-343.

MARGULIS, S.W. 1998. Relationships among parental inbreeding, parental behaviour and offspring viability in oldfield mice. Animal Behaviour 55: 427-438

MCCARTHY, J.C. 1967. The effects of inbreeding on the components of litter size in mice. Genetical Research 10: 73-80.

PACKER, C., and A.E. PUSEY. 1993. Dispersal, kinship and inbreeding in African lions. In: The Natural History of Inbreeding and Outbreeding: Theoretical and Empirical Perspectives (N.W. Thornhill, ed ) University of Chicago Press. Pp. 375-391.

PERIPARTO, A.C., R.A. DE BRITOR, T.T. VAUGHN, L.S. PLETSCHER, S.R. MATIOLI, and J.M. CHEVERUD. 2002. Quantitative trait loci for maternal performance for offspring survival in mice. Genetics 162: 1341-1353.

RALLS, K. K. BRUGGER and J. BALLOU. 1979. Inbreeding juvenile mortality in small populations of ungulates. Science 206: 1101-1103

RAMIREZ, O., L, ALTET, C. ENSENAT, C.VILÁ, A. SANCHEZ, and A. RUIZ. 2006. Genetic assessment of the Iberian wolf Canis lupus signatus captive breeding program. Conservation Genetics 7: 861-878.

READ, A.F. and P.H HARVEY. 1986. Genetic management in zoos. Nature 322: 408-410.

RICHARDS, C.M. 2000. Inbreeding depression and genetic rescue in a plant metapopulation. American Naturalist 155: 383-394. 
RODRIGAÑEZ, J., M.A. TORO, C. RODRIGUEZ and L. SILIÓ. 1998. Effect of founder allele survival and inbreeding depression on litter size in a closed line of Large White pigs. Animal Science 67: 573-582.

VAN ARENDONK, J.A M., C. VAN ROSMUELEN, L.L.G. JANSS and E.F. KNOL. 1996. Estimation of direct and maternal genetic co(variances) for survival within litters of piglets. Livestock Production Science 46: 163-171.

WRIGHT, L.I., T. TREGENZA AND D.J. HOSKEN. 2008. Inbreeding, inbreeding depression and extinction. Conservation Genetics 9: 833-843. 